\title{
Possíveis influências da elaboração de desenhos sobre narrativas infantis
}

\author{
Análise de narrativas infantis \\ Maria do Rosário de Fátima Rodrigues \\ Sávio Silveira de Queiroz \\ Heloisa Moulin de Alencar
}

\section{Resumo}

Analisaram-se narrativas de 60 crianças, comparando-se suas características, com o desenho do cenário antes e depois da história, divididas nas seguintes situações de produção: 15 alunos de 7 anos (da $1^{\mathrm{a}}$ série) e 15 de 9 anos (da $3^{\mathrm{a}}$ série) desenharam um cenário em um editor de imagens, para basear uma história que foi escrita posteriormente por eles no editor de textos; 15 alunos, de cada uma das idades e séries mencionadas, realizaram essas atividades inversamente. Os resultados indicaram que a situação desenho antes influenciou o aparecimento das características "explicação causal" e "desfecho elaborado" nas narrativas das crianças de 7 anos; e "resolução da situação-problema explicada" nas narrativas das crianças de 9 anos. A situação desenho depois influenciou, nas narrativas das crianças de 7 anos, o surgimento das características "explicação mágica" e "resolução da situação-problema sem coerência"; e entre as crianças de 9 anos, a característica "desfecho com mudança de tópicos".

Palavras-chave: narrativa; desenho; produção.

\section{Possible influences of the elaboration of drawings on children narratives}

\begin{abstract}
There was an analysis of 60 narratives made by children, comparing their characteristics with drawings of the setting, before and after the story, divided in the following situations of production: 15 students of 7 years old, from first grade (1st grade) and 15 of 9 years old, from third grade (3rd grade), drawn a setting in a image editor for a story that has been written by them in a text editor; 15 students, of each age and grade mentioned, realized these same activities inversely. The results indicate that the situation drawing-before had influence on the apparitions of the characteristics "causal explanation" and "elaborated ending" in the narratives of 7-years old children, and the "resolution of the situation-problem explained" in the narratives of 9-years old children. The situation drawing-after influenced, in the narratives of 7-years old children, the appearance of characteristics of "magical explanation" and "solving the situation-problem without coherence", and between the 9-years old children, the characteristics "ending with topic changes".
\end{abstract}

Keywords: narratives; drawing; production.

\section{Posibles influencias de la elaboración de dibujos sobre narraciones infantiles}

\begin{abstract}
Resumen
Se analizaron narraciones de 60 niños comparando sus características con el dibujo del escenario antes y después de la historia, divididas en las siguientes situaciones de producción: 15 alumnos de 7 años (del $1^{\circ}$ grado) y 15 de 9 años (del $3^{\circ}$ grado) dibujaron un escenario en un editor de imágenes para basar una historia que fue escrita posteriormente por ellos en el editor de textos; 15 alumnos de cada una de las edades y grados mencionados realizaron esas actividades inversamente. Los resultados indicaron que la situación dibujo antes influenció el aparecimiento de las características "explicación causal” y "desenlace elaborado" en las narraciones de los niños de 9 años. En las narraciones de los niños de 7 años, la situación dibujo después tuvo influencia en la aparición de las características "explicación mágica" y "resolución de la situación-problema sin coherencia"; y entre los niños de 9 años, la característica "desenlace con cambio de tema".

Palabras clave: narración; dibujo; producción.
\end{abstract}




\section{Introdução}

O ponto de partida do desenvolvimento da competência narrativa seria a brincadeira de faz-deconta, tendo como aliada a linguagem infantil que se parece com as fórmulas repetitivas e rimadas dos contos de fadas. Inicialmente, os cenários das histórias seriam concebidos como fantasiosos e os personagens preferidos seriam tidos como reais. Observa-se que as crianças menores possuem expectativas centradas na situação, nas ações que os personagens desempenham, interpretando a história como passado, real, e que, gradativamente, tornamse mais seqüenciais na descrição dos eventos e mais lógicas nas histórias. (Amaro \& Moreira, 2001).

Pillar (1996) constatou que, após o período de diferenciação do desenho e da escrita, no estágio da incapacidade sintética e no nível pré-silábico, há uma afinidade entre desenhar e escrever. Todavia, mesmo com uma linha evolutiva comum, a autora percebeu que pode haver, tanto uma correlação entre o desenho e a escrita, como uma precedência do desenho sobre a escrita, sugerindo que: assim como é possível encontrar correlação entre desenho e escrita é possível verificar, também, correlação entre desenhos e textos narrativos.

Nesta pesquisa buscou-se ampliar a compreensão do trabalho de Pillar (1996), a saber: se o desenho é uma atividade que influencia a construção de conhecimentos relativos à escrita, haveria influência de uma situação de produção do desenho em textos narrativos? Para tanto, tenta-se trabalhar sobre os seguintes objetivos: Identificar as características da narrativa das crianças de 7 anos; Identificar as características da narrativa das crianças de 9 anos; Comparar as características da narrativa das crianças de 7 anos com as características da narrativa das crianças de 9 anos; Comparar as características da narrativa das crianças de 7 anos, na situação de produção na qual o desenho tenha sido elaborado anteriormente à narrativa, com as características da narrativa das crianças de 7 anos, na situação de produção na qual o desenho tenha sido elaborado posteriormente à narrativa; Comparar as características da narrativa das crianças de 9 anos, na situação de produção na qual o desenho tenha sido elaborado anteriormente à narrativa, com as características da narrativa das crianças de 9 anos, na situação de produção na qual o desenho tenha sido elaborado posteriormente à narrativa.

Analisar-se-á, pois, a evolução da narrativa infantil em duas situações de produção (desenho antes e depois da história), destacando suas características, a saber: Inclusão de elementos mágicos, explicação mágica. Sincretismo, justaposição, elementos mágicos, explicação psicológica, resolução da situação-problema sem coerência, desfecho com mudança de tópicos, inclusão de personagens exteriores à história, explicação psicológica, explicação causal, resolução da situação-problema não explicada, desfecho não elaborado, intenção do personagem, resolução da situação-problema, implicação lógica, resolução da situação-problema explicada $\mathrm{e}$ desfecho elaborado.

Conforme Souza (2001), o sincretismo é um fenômeno que expressa a correspondência da falta de ligações objetivas a um excesso de ligações subjetivas no pensamento. Assim sendo, a criança liga tudo a tudo, sem que seja possível verificar as 
relações existentes entre os elementos. Isso ocorre porque o pensamento desconhece a lógica das relações, a adição e a multiplicação de classes lógicas, utilizando-se de ligações globais, não analisáveis. A autora considerou o sincretismo como uma das principais características de uma reconstituição fantasiosa de história, pois, neste tipo de reconstituição, a criança une idéias e sentimentos sem que se possa saber quais os elementos que uniu e por quais relações isso ocorreu.

Outra das características principais da reconstituição fantasiosa de histórias, segundo Souza (2001), é a justaposição, na qual a criança justapõe idéias na tentativa de compreender a história. Segundo a autora, a justaposição ocorre pela incapacidade de fazer sínteses e de compreender as relações entre parte e todo. Essa tendência pode ser observada na linguagem da criança, especialmente a pequena, na qual é notada a ausência de ligações entre os juízos sucessivos, pela ausência de conjunções.

Sobre a característica inclusão de elementos mágicos pode-se verificar, segundo Geist e Aldridge (2002), que esta é comum nas histórias que as crianças menores contam. Há progressão nas histórias que as crianças contam, em função das idades e séries escolares, de fantásticas, passando por narrativas fictícias, até se tornarem reais. Os autores analisaram histórias que as crianças criaram depois de terem participado de um "seminário dos contos de fadas", enfocando o personagem e organização das histórias e identificaram que, enquanto as crianças mais novas contavam histórias fantásticas de guarda-chuvas, planetas, magia e de bruxas más que transformavam crianças em comida, o segundo grupo contou histórias de ficção realista sobre caçadores, reis e rainhas, sendo que quase todas as histórias eram plausíveis e, finalmente, o terceiro grupo, de crianças maiores, tendeu a contar narrativas pessoais que se relacionavam diretamente às experiências de vida deles ou simplesmente contavam eventos que aconteceram a alguém.

Sobre a inclusão de personagens exteriores à história, em analogia com o trabalho de Souza (2001), é possível considerá-la como uma das características elementares de narrativas porque, segundo a autora, uma das tendências da reconstituição fantasiosa de história é a inclusão de elementos subjetivos ou externos à história, tais como, elementos de outras versões de uma história ou de outros contextos, para explicar as ações dos personagens ou eventos da história.

A intenção do personagem, por sua vez, de acordo com Souza (2001), se exemplifica por meio da reconstituição interpretativa de histórias que demonstra a inclusão de elementos inferidos a partir do conto, advindos das hipóteses feitas pela criança, para explicar as ações dos personagens ou eventos do enredo. Segundo a autora, as inferências podem referir-se às intenções dos personagens ou a indícios interpretados pela criança e por ela empregados para reconstituir a história. A intenção do personagem se vincula às relações de implicação mais do que de causa e efeito, o que sugere que as ações engendradas pelos personagens estão ligadas a uma formulação do tipo Se... Então..., a saber, 'se' determinado evento aconteceu, 'então' é provável que a consequiência que se seguiu tenha nele a sua razão. Logo, é possível extrair uma idéia de regra, abstraída no desenrolar da história. 
Além desta, a causalidade é uma das características que promovem o encadeamento das ações dos personagens e dos eventos das histórias. Devido a sua importância no desenrolar da história, foi analisada enquanto explicação mágica, explicação psicológica, explicação causal e implicação lógica, avaliadas, nessa ordem ascendente, como características que se manifestam evolutivamente nas narrativas.

De acordo com o trabalho de Souza (2001), é possível considerar a explicação mágica como uma das características elementares de uma narrativa, pois segundo a autora, uma das tendências da reconstituição fantasiosa de histórias é o emprego da causalidade mágica para explicar as ações dos personagens ou eventos da história. A explicação mágica implica em uma ação, motivação ou transformação mágica, como causa de um acontecimento ou motivação. Ao considerá-la como uma das características de uma narrativa fantástica, espera-se, por exemplo, que no decorrer do desenvolvimento das narrativas seja mais comum a explicação psicológica e a explicação causal.

Segundo Piaget (1966/1999), há uma espécie de explicação da causalidade que ao invés de esclarecer um evento, mediante uma causa material, o explica por meio de uma ação ou estado psicológico. A esse tipo de explicação o autor chamou de motivação. Trata-se de quando a criança procura nos fatos não uma causa material propriamente dita, mas a intenção, o motivo que levou à ação e, às vezes, à causa psicológica. Souza (2001) observou na reconstituição verbal de contos a presença de relações causais denominadas psicológicas, visto se referirem, segundo a autora, a estados motivacionais como causas para ações ou eventos. Mas, a palavra explicação, em Piaget (1966/1999), é adotada em um sentido de explicação causal ou final, que significa traçar pelo pensamento a causa dos fenômenos, quer essas causas sejam eficientes ou finais, conforme se trate de fenômenos naturais ou de máquinas.

Com efeito, para se compreenderem os eventos de uma história é necessário inferir as causas físicas e psicológicas que relacionam um evento com outro. Considera-se que o uso do conhecimento sobre os planos para alcançar um objetivo ou raciocínio causal conduz a estruturar uma sequiência de eventos, em um episódio, dando-lhe coerência. Para compreender a estrutura de um conto é necessário realizar inferências causais. Descrever as causas e determinar as conseqüências dos eventos conduz a organizar o conto em uma rede de eventos e não a considerá-lo como uma série desconectada de fatos. Neste sentido, a coerência da história se determina, em parte, no plano da causalidade. $O$ aumento do número de conexões causais que as crianças podem realizar implica em um avanço na compreensão dos eventos (Borzone, 2005). De acordo com Rosemberg (1994), mesmo que as crianças antes dos 6 anos possam produzir histórias com algum episódio baseado em um objetivo, é somente depois dos 8 anos que recuperam os objetivos em forma similar aos dos adultos. O padrão evolutivo neste aspecto se caracteriza pelo desenvolvimento gradual da habilidade para reconhecer múltiplas relações causais e para reconhecer as causas psicológicas. Assim, as crianças recuperam e codificam informação sobre quem, quando e onde os eventos sucederam, sobre o que estava se passando e o porquê e qual o resultado daquilo que se passou. Isso quer dizer 
que, ao recuperarem todos estes elementos, podem organizar os eventos em uma estrutura episódica coerente.

Além das ligações causais, existem nas narrativas ligações de implicação, que ligam não um fato a outro fato, mas uma razão a uma conseqüência ou um conceito a seu antecedente lógico. De acordo com Piaget (1967/sd), todo ato de inteligência socializada implica não somente na consciência de uma direção determinada do pensamento, mas ainda na consciência das ligações entre as afirmações sucessivas do relato, que são as ligações de implicação. Conforme o autor, é somente depois de 7-8 anos, quando do declínio do realismo, que os diversos tipos de ligação começam a se diferenciar, e que a relação de implicação lógica torna-se autônoma. Segundo Souza (2001), na reconstituição interpretativa de contos de fadas, as crianças empregam relações de implicação mais do que de causa e efeito. Trata-se de uma formulação do tipo Se... Então..., a saber, 'se' determinado evento aconteceu, 'então' é provável que a conseqüência que se seguiu tenha nele a sua razão. Assim, é possível extrair uma idéia de regra, abstraída no desenrolar da história.

Para se avançar um pouco mais nessa descrição evolutiva, será citada a pesquisa de Brandão e Spinillo (1998) na qual examinaram a relação entre o tipo de resposta fornecido e os elementos estruturais de uma história, a saber: situaçãoproblema, resolução da situação-problema e conclusão. As autoras apresentaram tarefas de reprodução de uma história ouvida e perguntas inferenciais sobre a mesma história a 40 crianças, divididas em dois grupos de idade: 4 e 6 anos. Observaram que, aos 4 anos, as respostas consideradas corretas foram mais frequientes diante das perguntas relacionadas à identificação da situação-problema do que nas perguntas sobre a resolução da situação-problema e consequiência ou desfecho. Aos 6 anos, as respostas precisas ocorreram mais nas questões relacionadas à identificação da situação-problema e à conseqüência, ou desfecho, do que nas perguntas sobre a resolução da situação-problema.

Como visto, há uma diferença evolutiva, quanto à identificação dos elementos estruturais de uma história. Assim, a fim de acompanhar a evolução da resolução da situação-problema nas narrativas desta pesquisa, essa evolução será descrita por meio do sistema de análise de Silva e Spinillo (2000), a partir do qual se considera que são mencionadas as seguintes características: resolução da situaçãoproblema sem coerência, resolução da situaçãoproblema não explicada e resolução da situaçãoproblema explicada, articuladas aos outros elementos estruturais de uma narrativa, como a situação-problema e conclusão. Dessa forma, foram enfatizadas algumas características da resolução da situação-problema nas narrativas. Entretanto, para finalizar essa descrição evolutiva, serão mencionadas as características do desfecho de uma história, por meio do sistema de análise de Spinillo e Martins (1997), a partir do qual as seguintes características são abordadas: desfecho com mudança de tópicos, desfecho não explicado e desfecho elaborado. Em análise da produção verbal de histórias coerentes de crianças, entre 6-7 anos, Spinillo e Martins (1997) verificaram que crianças nesta faixa-etária têm dificuldades em definir e manter o tópico ao longo da narrativa, e, principalmente, em elaborar um desfecho 
relacionado com o evento principal e os episódios narrados. Segundo os autores, o desfecho parece ser o indicador mais difícil de ser estabelecido na produção de uma história coerente. Desfechos elaborados são geralmente observados em histórias com outros indicadores, também elaborados, como por exemplo, personagens, eventos e tópicos da narração definidos e mantidos no decorrer da história, que são favoravelmente influenciados pela aquisição da leitura e da escrita.

A partir desses trabalhos optou-se, nesta pesquisa, por propor à criança que fizesse um desenho que representasse o cenário no qual aconteceria uma história a ser escrita por ela. Dessa forma, esperava-se que a situação de produção constituída como um desenho cenário demandasse da criança a representação do espaço no qual se desenrolariam possíveis eventos causais a serem descritos na elaboração da história. Nesse caso, acreditava-se que o desenho antes da história, como cenário, seria uma situação de produção favorável à manifestação de narrativas elaboradas, ou seja; imaginar o cenário da história e desenhá-lo, influenciaria a produção do texto narrativo.

Considerando-se o exposto, o presente trabalho teve por objetivo analisar, em uma perspectiva psicogenética, a produção de textos narrativos, elaborados por crianças de 7 e 9 anos, que cursavam a $1^{\mathrm{a}}$ e $3^{\mathrm{a}}$ série, respectivamente, por meio da comparação das características e dos níveis da narrativa com a elaboração do desenho do cenário da história, antes e depois da produção do texto narrativo.

\section{Método}

Os participantes desta pesquisa foram 60 crianças (36 meninas e 24 meninos), com 7 e 9 anos, alunos da $1^{\text {a }}$ e $3^{\text {a }}$ séries do ensino fundamental, de duas escolas particulares, de uma cidade do interior de Minas Gerais.

Utilizou-se como instrumento de coleta de dados o 'software' "Recontando Histórias" (Gomes \& Rodrigues, 2005), composto de nove contos de fadas tradicionais, oito atividades, cinco curiosidades e dois estudos, acessados a partir da tela principal, ilustrada com um cenário comum para todos os contos. Ressalta-se que somente duas atividades foram utilizadas na presente pesquisa, as quais serão apresentadas a seguir.

Na primeira etapa do procedimento, os alunos de cada série participaram, em sala de aula, de uma exposição dialogada sobre a estrutura básica de uma narrativa que, conforme Ferreira e Spinillo (2003), consistiu na instrução explícita sobre as partes de uma história: início, meio e fim, e do que tratam: os personagens e o lugar onde as situações acontecem, os acontecimentos propriamente ditos e finalmente, a resolução da situação-problema. Quanto ao desenho, foram enfatizadas as características do cenário de uma história, como o espaço onde acontecem as narrativas. A segunda etapa do procedimento ocorreu no laboratório de informática onde a instrução e a própria coleta de dados diferenciaram-se de acordo com a situação de produção do texto narrativo e desenho, a saber: Em uma $1^{\mathrm{a}}$ e $3^{\mathrm{a}}$ série, 15 alunos de 7 e de 9 anos, desenharam um cenário, para uma história que foi 


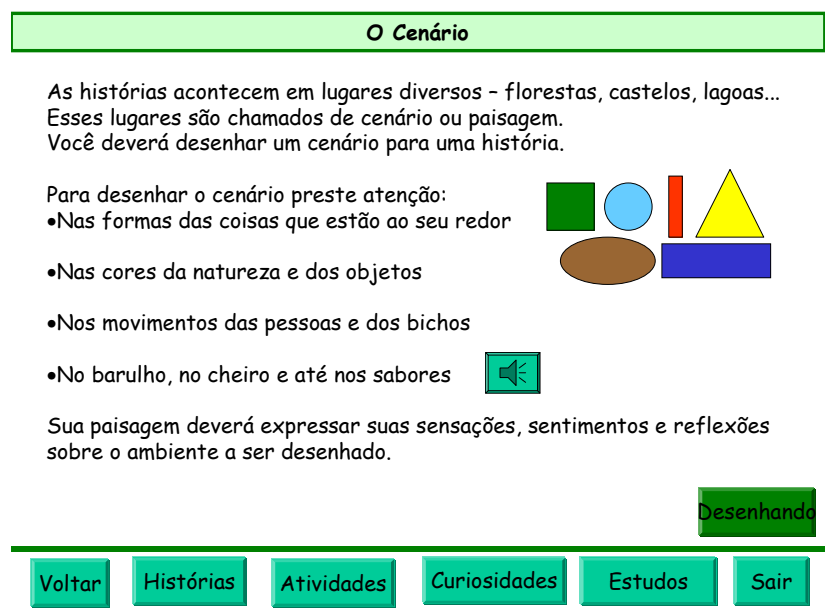

Figura 1. Cenário

\begin{tabular}{l} 
Escrevendo uma história \\
No início da história, geralmente, o narrador descreve o cenário e o \\
personagem. \\
No Meio da história há uma descrição de uma situação. \\
Imagine uma situação para sua história. Um fato, uma cena (aventura, emoções, \\
suspense, encontros...) \\
Pense nas causas dessa situação. O porquê; os fatores que contribuíram para o \\
acontecimento. \\
Preveja as conseqüências dessa situação. O que o acontecimento provocou. \\
No Fim da história, geralmente, há a resolução da situação que foi descrita. \\
Para escrever sua história clicar no botão Escrevendo \\
\hline Voltar Histórias
\end{tabular}

Figura 2. História

escrita posteriormente por eles; em outra $1^{\mathrm{a}}$ e $3^{\mathrm{a}}$ série, 15 alunos de 7 e de 9 anos, escreveram uma história, para um cenário que foi desenhado posteriormente por eles. O tempo utilizado para a instrução na sala de aula foi de 1hora/aula. Os participantes realizaram as atividades de desenho e escrita, no laboratório, em média durante dois encontros, sendo 1 hora/aula por semana.

\section{Tratamento dos dados}

As narrativas foram lidas em conjunto por um grupo de pesquisadores. No decorrer da primeira leitura foram elaboradas as categorias detalhadas, de análise das narrativas. A seguir, elaboraram-se as categorias resumidas. Então, cada narrativa foi analisada separadamente. As categorias detalhadas foram utilizadas predominantemente na análise 
qualitativa, e as resumidas, na quantitativa. $\mathrm{Na}$ contagem das características utilizou-se o critério do somatório. Tal critério possibilitou a divisão das narrativas naquelas que apresentaram mais ou menos vezes a mesma característica. Os dados considerados como não são aderentes à distribuição normal, foram tratados pelo programa SPSS (Statistical Package for Social Sciences). Utilizaram-se análises não-paramétricas que, ao invés de utilizarem a média e o desvio padrão que são os parâmetros da distribuição normal, utilizam a ordem dos valores para caracterizá-los, criando rankings entre eles, pois a média não os representa bem. As análises inferenciais utilizadas foram baseadas em teste de significância, em abordagem não-paramétrica, quando se trabalhou com variável quantitativa, em duas estratégias: Teste de MannWhitney - verificando se houve diferença significativa no somatório de determinada característica na mesma narrativa; Teste exato de Fisher - permitiu calcular a probabilidade de associação das características em análise, ou seja, a probabilidade de tais características serem independentes, mesmo com número total de dados pequeno, produzindo erro menor do que se fosse utilizado o teste de Qui Quadrado.

\section{Resultados}

Considerando a usual limitação de páginas para apresentação de qualquer artigo científico, apresentar-se-ão os resultados em função de cada objetivo traçado, destacando textualmente das tabelas apenas os itens em que houve diferença estatística significante (para valores de $p<0,05$ ).
Os objetivos específicos 1,2 e 3 foram tratados a partir dos resultados apontados nas tabelas 1, 2 e 3.

Perguntou-se, então, se a mudança das idades alteraria significativamente as características das narrativas. Essas respostas enfocaram a presença da característica e o seu somatório, ou seja, se determinada característica apareceu na narrativa de cada participante, e quantas vezes a mesma característica apareceu na narrativa, conforme demonstrado na Tabela 1 e Tabela 2, respectivamente, nas quais o valor de $p<0,05$. A explicação psicológica apareceu nas narrativas de dez participantes de 7 anos e 18 participantes de 9 anos. Observou-se essa característica 15 vezes nas narrativas das crianças de 7 anos e 37 vezes nas narrativas das crianças de 9 anos. De acordo com o teste exato de Fisher $(p=0,035)$ e teste MannWhitney $(p=0,033)$, utilizados na análise comparativa entre as idades dos alunos, a variável idade influenciou significativamente a presença e o somatório da característica explicação psicológica.

Para atender ao estabelecido pelos objetivos específicos 4 e 5 , bem como apreender mais detalhadamente o sentido das narrativas, ver-se-ão as mesmas características de acordo com a situação de produção. Dessa maneira, formular-se-ão as mesmas questões em função da situação de produção. Será que o fato de fazer a narrativa antes ou depois do desenho interfere significativamente em suas características? Essas respostas enfocaram a presença das características e o seu somatório, ou seja, se determinada característica apareceu na narrativa de cada participante, e quantas vezes uma característica apareceu na mesma narrativa, conforme demonstrado na Tabela 3 e Tabela 4, respectivamente, nas quais o valor de $p<0,05$. 
Tabela 1. Comparações da presença das características nas narrativas segundo as idades.

\begin{tabular}{|c|c|c|c|c|c|}
\hline \multirow{2}{*}{ Características das narrativas } & \multicolumn{2}{|c|}{7 anos } & \multicolumn{2}{|c|}{9 anos } & \multirow{2}{*}{$\begin{array}{l}\text { Teste exato } \\
\text { de Fisher }\end{array}$} \\
\hline & $\mathrm{N}$ & $\%$ & $\mathrm{~N}$ & $\%$ & \\
\hline Sincretismo & 2 & 6,7 & 7 & 23,3 & 0,073 \\
\hline Justaposição & 11 & 36,7 & 11 & 36,7 & 1,000 \\
\hline Inclusão de elementos mágicos & 11 & 36,7 & 8 & 26,7 & 0,290 \\
\hline $\begin{array}{l}\text { Inclusão de personagens exteriores à } \\
\text { história }\end{array}$ & 5 & 16,7 & 1 & 3,3 & 0,097 \\
\hline Intenção do personagem & 2 & 6,7 & 1 & 3,3 & 0,500 \\
\hline Explicação mágica & 4 & 13,3 & 2 & 6,7 & 0,335 \\
\hline Explicação psicológica & 10 & 33,3 & 18 & 60,0 & $\begin{array}{c}0,035 \\
(p<0,05)\end{array}$ \\
\hline Explicação causal & 15 & 50,0 & 20 & 66,7 & 0,147 \\
\hline Implicação lógica & 3 & 10,0 & 3 & 10,0 & 1,000 \\
\hline $\begin{array}{l}\text { Resolução da situação-problema sem } \\
\text { coerência }\end{array}$ & 4 & 13,3 & 3 & 10,0 & 0,500 \\
\hline $\begin{array}{l}\text { Resolução da situação-problema não } \\
\text { explicada }\end{array}$ & 11 & 36,7 & 11 & 36,7 & 1,000 \\
\hline $\begin{array}{l}\text { Resolução da situação-problema } \\
\text { explicada }\end{array}$ & 7 & 23,3 & 12 & 40,0 & 0,133 \\
\hline Desfecho com mudança de tópicos & 3 & 10,0 & 4 & 13,3 & 0,500 \\
\hline Desfecho não elaborado & 18 & 60,0 & 20 & 66,7 & 0,395 \\
\hline Desfecho elaborado & 8 & 26,7 & 6 & 20,0 & 0,381 \\
\hline
\end{tabular}

A comparação entre as duas situações de produção e a explicação mágica, apresentada nas narrativas, foi estatisticamente significativa, segundo o teste exato de Fisher $(p=0,05)$, dentre as narrativas das crianças de 7 anos. A comparação entre as duas situações de produção e o somatório dessa característica, apresentada nas narrativas das crianças de 7 anos, também foi estatisticamente significativa, conforme o teste Mann-Whitney $(p=0,035)$.

Quanto à característica explicação causal, apresentada nas narrativas, foi estatisticamente significativa conforme o teste exato de Fisher $(p=0,013)$, dentre as narrativas das crianças de 7 anos, sendo também estatisticamente significativa conforme o teste Mann-Whitney $(p=0,012)$, no somatório da mesma característica.

Por meio do teste exato de Fisher foi possível verificar que, ao se comparar a presença da característica resolução da situação-problema sem coerência, houve diferença significativa $(p=0,050)$, segundo as situações de produção, dentre as narrativas das crianças de 7 anos. Ressalta-se que, 
Tabela 2. Comparações do somatório das características nas narrativas conforme as idades.

\begin{tabular}{lccc}
\hline Características das narrativas & $\begin{array}{c}7 \\
\text { anos }\end{array}$ & 9 anos & $\begin{array}{c}\text { Teste Mann- } \\
\text { Whitney }\end{array}$ \\
\hline Sincretismo & 2 & 9 & 0,066 \\
Justaposição & 24 & 13 & 0,723 \\
Inclusão de elementos mágicos & 18 & 12 & 0,418 \\
Inclusão de personagens exteriores à história & 5 & 1 & 0,088 \\
Intenção do personagem & 3 & 1 & 0,544 \\
Explicação mágica & 4 & 4 & 0,460 \\
Explicação psicológica & 15 & 37 & 0,033 \\
& & & $(p<0,05)$ \\
Explicação causal & 16 & 28 & 0,049 \\
Implicação lógica & 3 & 4 & 0,966 \\
Resolução da situação-problema sem coerência & 4 & 3 & 0,690 \\
Resolução da situação-problema não explicada & 11 & 11 & 1,000 \\
Resolução da situação-problema explicada & 8 & 13 & 0,186 \\
Desfecho com mudança de tópicos & 3 & 4 & 0,690 \\
Desfecho não elaborado & 18 & 20 & 0,595 \\
Desfecho elaborado & 8 & 6 & 0,545 \\
\hline
\end{tabular}

por meio do teste Mann-Whitney, foi possível observar que, ao se comparar o somatório da característica resolução da situação-problema sem coerência, houve diferença significativa ( $p=0,035)$, segundo as situações de produção, também dentre as narrativas das crianças de 7 anos. Enfatiza-se que somente nas narrativas escritas antes do desenho apareceu a característica resolução da situação-problema sem coerência.

Será visto a seguir se o fato da criança elaborar uma narrativa antes ou depois do desenho altera a característica resolução da situação-problema explicada. A comparação entre as duas situações de produção e a presença dessa característica, apresentada nas narrativas, foi estatisticamente significativa, segundo o teste exato de Fisher $(p=0,030)$, dentre as narrativas das crianças de 9 anos. Ressalta-se que a comparação entre as duas situações de produção no somatório da característica resolução da situação-problema explicada, apresentada nas narrativas, também foi estatisticamente significativa, segundo $o$ teste Mann-Whitney, $(p=0,025)$, dentre as narrativas das crianças de 9 anos. Enfatiza-se que essa característica prevaleceu nas narrativas escritas depois do desenho.

De acordo com o teste exato de Fisher, utilizado na análise comparativa entre as situações de produção, a variável situação de produção influenciou significativamente a presença da 
Tabela 3. Comparações da presença das características nas narrativas segundo as situações de produção.

\begin{tabular}{lccc}
\hline Características das narrativas & $\begin{array}{c}7 \text { anos - Teste exato } \\
\text { de Fisher }\end{array}$ & & $\begin{array}{c}9 \text { anos - Teste exato } \\
\text { de Fisher }\end{array}$ \\
\cline { 2 - 3 } Sincretismo & $\begin{array}{c}\text { Narrativa antes e } \\
\text { depois do desenho }\end{array}$ & & $\begin{array}{c}\text { Narrativa antes e } \\
\text { depois do desenho }\end{array}$ \\
Justaposição & 0,241 & 0,500 \\
Inclusão de elementos mágicos & 0,225 & 0,225 \\
Inclusão de personagens exteriores à história & 0,225 & 0,341 \\
Intenção do personagem & 0,165 & 0,500 \\
Explicação mágica & 1,000 & 0,500 \\
Explicação psicológica & $0,050(\mathrm{p}=0,05)$ & \\
Explicação causal & 0,350 & 1,000 \\
Implicação lógica & $0,013(\mathrm{p}=0,05)$ & & 0,132 \\
Resolução da situação-problema sem coerência & $0,050(\mathrm{p}=0,05)$ & & 0,350 \\
Resolução da situação-problema não explicada & 0,358 & 0,112 \\
Resolução da situação-problema explicada & 0,195 & & 0,358 \\
Desfecho com mudança de tópicos & 0,112 & $0,030(\mathrm{p}=0,05)$ \\
Desfecho não elaborado & 0,132 & $0,050(\mathrm{p}=0,05)$ \\
Desfecho elaborado & $0,018(\mathrm{p}=0,05)$ & 0,650 \\
\hline
\end{tabular}

característica desfecho com mudança de tópicos $(p=0,050)$, dentre as narrativas das crianças de 9 anos. De acordo com o teste Mann-Whitney, o somatório dessa característica teve sua manifestação influenciada pela situação de produção $(p=0,035)$, também dentre as narrativas das crianças de 9 anos. Enfatiza-se que a característica desfecho com mudança de tópicos apareceu somente nas narrativas escritas antes do desenho.

O teste exato de Fisher, empregado para a análise comparativa entre as situações de produção, permitiu evidenciar que houve diferença estatística da presença de desfecho elaborado $(p=0,018)$, quando se comparou essa característica em narrativas elaboradas antes e depois do desenho, pelas crianças de 7 anos. Ressalta-se que a comparação entre as duas situações de produção no somatório da característica desfecho elaborado, apresentada nas narrativas, foi estatisticamente significativa, segundo o teste Mann-Whitney, $(p=0,015)$, somente dentre as narrativas das crianças de 7 anos. Ressalta-se que a característica desfecho elaborado prevaleceu nas narrativas escritas na situação desenho antes. 
Tabela 4. Comparações do somatório das características nas narrativas conforme as situações de produção.

\begin{tabular}{lcccc}
\hline Características das narrativas & $\begin{array}{c}7 \text { anos - Teste } \\
\text { Mann-Whitney }\end{array}$ & & $\begin{array}{c}9 \text { anos - Teste } \\
\text { Mann-Whitney }\end{array}$ \\
\cline { 2 - 2 } Sincretismo & $\begin{array}{c}\text { Narrativa antes e } \\
\text { depois do desenho }\end{array}$ & $\begin{array}{c}\text { Narrativa antes e } \\
\text { depois do desenho }\end{array}$ \\
Justaposição & 0,150 & 0,555 \\
Inclusão de elementos mágicos & 0,359 & 0,195 \\
Inclusão de personagens exteriores à história & 0,140 & 0,487 \\
Intenção do personagem & 0,148 & 0,317 \\
Explicação mágica & 0,962 & 0,317 \\
Explicação psicológica & $0,035(p<0,05)$ & 1,000 \\
Explicação causal & 0,410 & 0,234 \\
Implicação lógica & $0,012(p<0,05)$ & 0,347 \\
Resolução da situação-problema sem coerência & $0,035(p<0,05)$ & & 0,073 \\
Resolução da situação-problema não explicada & 0,472 & 0,472 \\
Resolução da situação-problema explicada & 0,185 & & $0,025(p<0,05)$ \\
Desfecho com mudança de tópicos & 0,073 & $0,035(p<0,05)$ \\
Desfecho não elaborado & 0,143 & 1,000 \\
Desfecho elaborado & $0,015(p<0,05)$ & 0,073 \\
\hline
\end{tabular}

\section{Discussão}

Dos resultados gerais, um dos pontos que chama atenção para ser discutido é que a influência da situação de produção desenho antes e depois da narrativa foi diferente entre as idades. Observou-se que a situação de produção desenho antes favoreceu a manifestação das características explicação causal e desfecho elaborado, dentre as narrativas das crianças de 7 anos, e, resolução da situaçãoproblema explicada, dentre as narrativas das crianças de 9 anos. E, a situação de produção desenho depois favoreceu a manifestação das características explicação mágica e resolução da situação-problema sem coerência, dentre as narrativas das crianças de 7 anos, e, desfecho com mudança de tópicos, dentre as narrativas das crianças de 9 anos.

A situação de produção influenciou características típicas da causalidade infantil, como explicação mágica e explicação causal, dentre as narrativas das crianças de 7 anos, enquanto as crianças de 9 anos não demonstraram em suas narrativas a influência da situação de produção nas características típicas da causalidade infantil. E, nas duas idades, a situação de produção influenciou características típicas da narrativa, como resolução da situação-problema sem coerência, resolução da situação-problema explicada, desfecho com 
mudança de tópicos e desfecho elaborado. As situações de produção e as idades, analisadas em conjunto, permitiram verificar que a situação de produção influenciou a causalidade das narrativas, somente na idade de 7 anos e influenciou características típicas da narrativas, diferentemente, em função da idade, a saber: o desenho antes da narrativa facilitou a emergência de resolução explicada da situação-problema, nas narrativas das crianças de 9 anos, e a emergência de desfecho elaborado nas narrativas das crianças de 7 anos. Inversamente, a situação de produção desenho depois influenciou a emergência de uma resolução da situação-problema sem coerência nas narrativas das crianças de 7 anos, e a emergência de um desfecho com mudança de tópicos nas narrativas das crianças de 9 anos. Sobre esses pontos de discussão, os dados permitiram aferir uma tendência à concordância entre a evolução da narrativa e algumas das suas características típicas como resolução da situação-problema e desfecho, influenciadas pela situação de produção, variando entre as idades, e, finalmente, a concordância entre evolução da causalidade e da narrativa em função da idade de 7 anos e situação de produção desenho antes e depois.

Assim, de forma geral, os alunos, de 7 e 9 anos, que estiveram sujeitos à situação de produção desenho depois, apresentaram predominantemente a resolução da situação-problema sem coerência e mudança de tópicos, características que culminaram em uma narrativa elementar; enquanto entre os alunos de 7 e 9 anos que estiveram sujeitos à situação de produção desenho antes, houve maior incidência do desfecho elaborado e resolução da situação-problema explicada, características que culminaram em uma narrativa elaborada. Conforme foi identificado, as narrativas das crianças de 7 anos apresentaram na situação de produção desenho depois, significativamente, as características explicação mágica e resolução da situaçãoproblema sem coerência, diferentemente das narrativas das crianças de 9 anos, na mesma situação de produção, que apresentaram, significativamente, a característica desfecho com mudança de tópicos. Na situação de produção desenho antes, as narrativas das crianças de 7 anos apresentaram, significativamente, as características explicação causal e desfecho elaborado; enquanto as narrativas das crianças de 9 anos, na mesma situação de produção, apresentaram, significativamente, a característica resolução da situação-problema explicada.

Esses dados permitiram verificar uma tendência à concordância entre idade e aspectos evolutivos da narrativa. Assim, de uma forma geral, as crianças de 7 anos apresentaram significativamente, nas narrativas escritas na situação de produção desenho depois, uma característica relativa à noção de causalidade e outra característica relativa ao tipo do desfecho de uma narrativa. As crianças de 9 anos apresentaram, significativamente, na mesma situação de produção, uma característica relativa ao tipo da resolução de uma situação-problema da narrativa.

Dos resultados apresentados sobre a característica desfecho elaborado, a relevância recaiu sobre o aumento significativo da sua manifestação nas narrativas das crianças de 7 anos escritas na situação desenho antes. Segundo Spinillo e Martins (1997), o desfecho parece ser o indicador mais difícil de ser estabelecido na 
produção de histórias coerentes. $\mathrm{Na}$ análise da produção de histórias coerentes de crianças, entre 67 anos, os autores verificaram que elas, nesta faixaetária, têm dificuldades em definir e manter o tópico ao longo da narrativa, e, principalmente, em elaborar um desfecho relacionado com o evento principal e os episódios narrados. De acordo com as autoras, acredita-se que as narrativas que apresentaram a característica desfecho elaborado, especialmente das crianças de 7 anos, da $1^{a}$ série, foram influenciadas pela situação de produção desenho antes. Ou seja, supõe-se que nas narrativas das crianças de 7 anos, a situação, com apoio narrativo, favoreceu a emergência de um tipo de desfecho, ainda difícil de ser alcançado nessa idade.

Sobre as narrativas das crianças de 9 anos que evidenciaram, significativamente, resolução da situação-problema explicada, na situação de produção desenho antes, supõe-se que essa característica seja mais suscetível de ser influenciada nessa idade. Essa hipótese fundamenta-se em pesquisa de Brandão e Spinillo (1998) na qual se examinou a relação entre o tipo de resposta fornecido e os elementos estruturais de uma história, a saber: situação-problema, resolução da situação-problema e conclusão. As autoras identificaram que, nas crianças de 4 anos de idade, as respostas precisas foram mais freqüentes diante das perguntas relacionadas à situação-problema do que nas perguntas sobre a resolução do problema e conseqüência; aos 6 anos, as respostas precisas ocorreram mais nas questões relacionadas à situação-problema e à conseqüência do que nas perguntas sobre a resolução do problema.

Em analogia com essa pesquisa, pode-se supor que esse padrão evolutivo se mantém, a saber: os elementos estruturais da história seriam apreendidos pelas crianças, na seguinte ordem: situaçãoproblema, desfecho e resolução da situaçãoproblema. Nesse contexto, enquanto o desfecho seria a característica mais importante a ser desenvolvida nas narrativas das crianças de 7 anos, diferentemente, a resolução da situação-problema seria a característica mais importante a ser desenvolvida nas narrativas das crianças de 9 anos. Assim, a situação de produção desenho antes influenciaria características mais elaboradas de desfecho e resolução da situação-problema, nas narrativas das crianças de 7 e de 9 anos, respectivamente.

Outro ponto relevante para discussão foram as diferenças entre as crianças de 7 e 9 anos, no somatório das características das narrativas. De acordo com Piaget (1966/1999), dificilmente o estudo da causalidade pode ser feito isoladamente das representações infantis. Para esse autor, deve-se estudar a causalidade infantil, em parte, do ponto de vista da estrutura do raciocínio, mais particularmente a partir das influências do egocentrismo. Assim, por exemplo, pode-se perguntar se a criança sente como nós a necessidade de uma explicação causal. Essas considerações podem ser contextualizadas com a constatação de que a criança de 6 a 8 anos pouco se interessa pelo "como" as coisas acontecem. A sua curiosidade é global. "A vida orgânica é para a criança uma espécie de história, bem organizada ao sabor dos desejos e das intenções do seu inventor." (Piaget, 1966/1999, p.218). Antes dos 7 ou 8 anos, para as crianças, a explicação causal confunde-se com a motivação, tendo a causalidade um caráter finalista. Nesse caso, a criança evoca como causa dos 
fenômenos, motivos ou intenções, atribuindo razões às coisas. É por isso que se considera que as explicações infantis manifestam um realismo intelectual, pois o sentimento da necessidade precede a explicação.

Para que as crianças demonstrem a noção de causalidade, se o tempo é um dos fatores a indicar esse desenvolvimento, surge então o questionamento sobre a influência da situação de produção de um desenho do cenário antes da história, no aparecimento significativo da característica explicação causal, nas narrativas das crianças de 7 anos. Segundo Amaro e Moreira (2001) tal como acontece com o aprendizado da linguagem, a contribuição social é muito importante para o desenvolvimento da competência narrativa da criança e conseqüente capacidade para contar histórias. Segundo os autores, as crianças percebem rapidamente como os outros contam histórias e passam a utilizar os mesmos procedimentos, cada vez mais no decorrer do tempo. A apreensão da estrutura de uma narrativa, apesar de implicar uma complexidade a ser gerenciada pela criança, do ponto de vista cognitivo, para lidar com essa complexidade, fornece-lhe novas estratégias que se traduzem em técnicas diferentes da organização de personagens e eventos. Ao facilitar a imaginação simbólica da criança disponibilizando um espaço para o seu exercício, as atividades narrativas preparam o caminho para o desenvolvimento do pensamento abstrato. Assim sendo, se a capacidade de contar histórias for entendida como resultante do processo de interação da criança com os acontecimentos que vivencia e pessoas com as quais aprende a narrar, e se o exercício narrativo for considerado como uma atividade importante no desenvolvimento da própria capacidade de narrar, então, segundo os mesmos autores, é importante compreender aspectos dessa atividade, de tal maneira a serem fornecidos à criança novos mecanismos, técnicas e meios para que suas competências e inspirações encontrem maneiras mais ricas em expressão e desenvolvimento.

Ao investir neste problema de pesquisa acreditava-se que, ao propor a elaboração de histórias às crianças, a partir do desenho de um cenário, elas se envolveriam mais com a atividade, posto que as pistas dos objetivos das histórias que iriam escrever estariam assinaladas na revisão do cenário, com a colocação dos personagens em cena, para em seguida engendrarem as ações. Ao comporem uma narrativa, idealmente, com situação-problema, resolução da situação-problema e desfecho, expressando aí seus processos cognitivos e motivacionais, considerava-se que um dos aspectos importantes seria a explicação causal dos eventos. O resultado desta pesquisa sobre a noção de causalidade, como um aspecto passível de ser influenciado por uma situação de produção, soma-se favoravelmente ao fato de os educadores considerarem a produção das histórias infantis como um desafio na sua prática pedagógica. Nesse contexto, as situações de produção são também importantes fatores a serem considerados, quando se deseja examinar as habilidades que a criança possui e as dificuldades que experimenta. Assim, a situação de produção, veiculada pela ação de desenhar um cenário de uma história antes de escrevê-la, é um dos pequenos pontos que formam a diversidade de experiências com narrativas e desenhos. Sendo que essa situação demonstrou influenciar características elaboradas de uma 
narrativa. E é essa a tarefa do próprio exercício narrativo, ou seja, dar forma ao imaginário da criança, emprestando-lhe concretude de tal maneira a abrir caminho para o pensamento abstrato, sem que se perca a riqueza da imaginação, via ficção e arte.

Então, como as crianças podem escrever melhores narrativas em função de uma situação de produção? Essa foi a problemática estudada. O limite deste trabalho foi fornecer alguns dados sobre a emergência de características elaboradas em função da situação de produção desenho antes. $\mathrm{O}$ resultado que se obteve é que as crianças, ao demonstrarem em suas narrativas as características descritas, apresentaram, também, aspectos do seu próprio desenvolvimento. No entanto, nessa situação, tenderam também a expressarem características em função da própria evolução da narrativa. Logo, percebe-se que aspectos cognitivos e evolução da narrativa andam de mãos dadas. Ora, se as crianças estão suscetíveis a desenvolverem a noção de causalidade, a situação de produção favorável tende a influenciar da mesma forma. E assim sucessivamente, no que tange aos tipos de resolução e desfecho, como características das narrativas, ancoradas na idade e série escolar, como fatores favoráveis ao desenvolvimento da capacidade de contar histórias. Esse dado vem confirmar a importância de estudos não só sobre as situações de produção, mas, principalmente, sobre a adequação dessas situações às crianças, considerando o seu desenvolvimento.
A análise da discrepância desse resultado; a saber, a presença significativa de características elaboradas em narrativas na situação de produção desenho antes da narrativa e o fato das melhores narrativas das crianças de 7 anos terem aparecido na situação de produção desenho depois, indica, portanto, alguns caminhos para reflexão. O primeiro é a possibilidade de se realizar novos estudos com maior número de crianças, de idades diferentes, para identificar níveis de narrativas e perceber, se em decorrência da quantidade maior de narrativas, bem como a diversificação decorrente das idades, se há uma diferença significativa no fato de se realizar uma narrativa depois do desenho de um cenário. $\mathrm{O}$ segundo caminho para reflexão refere-se à possibilidade de se utilizar mais histórias de crianças em idades diferentes, no sentido de aperfeiçoar a própria formulação dos níveis, especialmente os da narrativa escrita, para os quais a literatura à qual se teve acesso foi menos abrangente do que para as histórias recontadas.

\section{Referências}

Amaro, A. C., \& Moreira, A. (2001). Quando as crianças contam histórias: compreensão dos processos de estruturação das histórias contadas por crianças do $1^{\circ} \mathrm{C}$. Em E. B. para a construção de um guião de uma ferramenta informática. II Conferência Internacional Challenges'2001/Desafios'2001. [On-line]. Disponível: http://www.nonio.uminho.pt/

Borzone, A. M. (2005). La lectura de cuentos en el jardín infantil: un medio para el desarrollo de estrategias cognitivas y lingüísticas. Psykhe, 14(1), 192-209.

Brandão, A. C. P., \& Spinillo, A. G. (1998). Aspectos 
gerais e específicos na compreensão de textos. Psicologia: Reflexão e Crítica, 11(2), 253-272.

Ferreira, A. L., \& Spinillo, A. G. (2003). Desenvolvendo a habilidade de produção de textos em crianças a partir da consciência metatextual. Em M. R. Maluf (Org.), Metalinguagem e aquisição da escrita: contribuições da pesquisa para a prática da alfabetização (pp. 119-148).

São Paulo: Casa do Psicólogo.

Geist, E., \& Aldridge, J. (2002). The developmental progression of children's oral story inventions. Journal of Instructional Psychology, 29(1), 33-37.
Gomes, M. A. F., \& Rodrigues, M. R. F. (2005). Recontando Histórias [CD-ROM].

Piaget, J. (1999). A linguagem e o pensamento da criança. (M. Campos, trad.). São Paulo: Martins Fontes. (Trabalho original publicado em 1966).

Piaget, J. (s/d). O raciocínio na criança. (V. R. Chaves, trad.). Rio de Janeiro: Record. (Trabalho original publicado em 1967).

Recebido em: 25/01/2008

Revisado em: 30/07/2008

Aprovado em: 06/08/2008

Sobre os autores:

Maria do Rosário de Fátima Rodrigues (rosariorodrigues@ click21.com.br) - Centro Universitário do Leste de Minas Gerais

Sávio Silveira de Queiroz (savioqueiroz@terra.com.br) - Universidade Federal do Espírito Santo

Heloisa Moulin de Alencar (hmoulin@terra.com.br) - Universidade Federal do Espírito Santo

Nota dos autores:

O artigo consiste em parte da tese de doutorado da primeira autora, sob as orientações dos segundos, com apoio da CAPES. Agradecimentos à Escola Educação Criativa e Colégio Padre de Man, pelo apoio na coleta de dados. 